\title{
Rice crop phenology mapping at high spatial and temporal resolution using downscaled MODIS time-series.
}

\author{
* Alex O. Onojeghuo a, b, George A. Blackburn a , Qunming Wang a, c, Peter M. Atkinson d, e, f, \\ Daniel Kindred ${ }^{g}$, Yuxin Miao ${ }^{\mathrm{h}}$ \\ a Lancaster Environment Centre, Lancaster University, Lancaster LA1 4YQ, United Kingdom
b Department of Surveying and Geoinformatics, Nnamdi Azikiwe University, Awka, Anambra State, Nigeria.
${ }^{c}$ Department of Land Surveying and Geo-Informatics, The Hong Kong Polytechnic University, Kowloon, Hong \\ Kong \\ ${ }^{\mathrm{d}}$ Faculty of Science and Technology, Engineering Building, Lancaster University, Bailrigg, Lancaster LA1 \\ 4YR, United Kingdom \\ e Faculty of Geosciences, University of Utrecht, Heidelberglaan 2, 3584 CS Utrecht, The Netherlands \\ ${ }^{\mathrm{f}}$ School of Geography, Archaeology and Palaeoecology, Queen's University Belfast, BT7 1NN, Northern \\ Ireland, United Kingdom \\ g ADAS UK Limited, Boxworth, Cambridge CB23 4NN, United Kingdom \\ h Department of Plant Nutrition, College of Resource and Environmental Sciences, China Agricultural \\ University, Beijing 100094, China
}

* Corresponding author e-mail: lexisgis@yahoo.com

\begin{abstract}
Satellite data holds considerable potential as a source of information on rice crop growth which can be used to inform agronomy. However, given the typical field sizes in many rice-growing countries such as China, data from coarse spatial resolution satellite systems such as the Moderate Resolution Imaging Spectroradiometer (MODIS) are inadequate for resolving crop growth variability at the field scale. Nevertheless, systems such as MODIS do provide images with sufficient frequency to be able to capture the detail of rice crop growth trajectories throughout a growing season. In order to generate high spatial and temporal resolution data suitable for mapping rice crop phenology this study fused MODIS data with lower frequency, higher spatial resolution Landsat data. An overall workflow was developed which began with image pre-processing, calculation of multi-temporal normalised difference vegetation index (NDVI) images and spatio-temporal fusion of data from the two sensors. The Spatial and Temporal Adaptive Reflectance Fusion Model was used to effectively downscale the MODIS data to deliver a time series of $30 \mathrm{~m}$ spatial resolution NDVI data at 8-day intervals throughout the rice growing season. Zonal statistical analysis was used to extract NDVI time-series for individual fields and signal filtering was applied to the time-series to generate rice phenology curves. The downscaled MODIS NDVI products were able to characterise the development of paddy rice at fine spatial and temporal resolutions, across wide spatial extents over multiple growing seasons. These data permitted the extraction of key crop seasonality parameters that quantified inter-annual growth variability for a whole agricultural region and enabled mapping of the variability in crop performance between and within fields. Hence, this approach can provide rice crop growth data that is suitable for informing agronomic policy and practice across a wide range of scales.
\end{abstract}

Keywords: NDVI, MODIS, Landsat, downscaling, spatio-temporal fusion, rice, phenology

\section{Introduction}


Rice is a major staple food for almost $50 \%$ of the world's population (Kuenzer and Knauer, 2013) and China accounts for $28 \%$ of global paddy rice production (FAOSTAT, 2014). Chinese government policy is focused on improving yields through production methods that increase both food security and environmental sustainability (Peng et al., 2009). Efforts to promote sustainable intensification of production through effective monitoring and better farming practice are highly important in China (Ju et al., 2004; Li et al., 2012), but there is a major challenge to generate and convey locally accurate information and advice to the very large number of farmers in the country. In particular, understanding the dynamics of the specific phenological stages of rice crops is key to informing strategic (pre-growing season) and tactical (within-growing season) management practices that can maximise production sustainably. Likewise, inter-annual variations of crop seasonality parameters can be controlled by factors such as climatic conditions and agricultural policy (Li et al., 2012; Reed et al., 1994; Sakamoto et al., 2010), but the ability to correctly determine these parameters is crucial for optimising agronomic practice. In this context, satellite remote sensing could potentially aid sustainable intensification in China by giving researchers and extension officers the tools to characterise the spatial and temporal variability in crop growth and understand the reasons for this variability at field, village and province scales, in order to target the sharing of best practice.

Satellite remote sensing is well proven as an effective means of discriminating different crop types (Chen et al., 2012; Fang, 1998; Forkuor et al., 2015; Karkee et al., 2009; Van Niel and McVicar, 2004; Zhang et al., 2015) and for monitoring crop phenology (Fangping et al., 2007; Ganguly et al., 2010; Pan et al., 2015; Potapov et al., 2008; Qiu et al., 2015; Sha et al., 2016; $\mathrm{Wu}$ et al., 2010). In particular, several studies have engaged in discriminating rice cropping systems using remotely sensed imagery over parts of China (Sakamoto et al., 2006; Xiao et al., 2006; Xiao et al., 2005). The use of vegetation indices to capture the spectral information contained in multi-temporal remotely sensed data has been shown to provide valuable information on the seasonal development of crops (Ganguly et al., 2010; Liang et al., 2011; $\mathrm{Wu}$ et al., 2010). The most common of these vegetation indices used in crop monitoring is the Normalised Difference Vegetation Index (NDVI) (Holben et al., 1980; Huete et al., 2002; Rouse et al., 1974; Tucker, 1979). Several studies have explored the use of satellite derived NDVI to measure vegetation health (Elmore et al., 2000; Lenney et al., 1996; Rouse Jr et al., 1974) and to estimate and predict crop yield (Kastens et al., 2005; Mkhabela et al., 2011; Ren et al., 2008). The availability of frequent satellite data as provided by the Advanced Very HighResolution Radiometer (AVHRR) (Kastens et al., 2005) and the Moderate Resolution Imaging Spectroradiometer (MODIS) (Huete et al., 2002; Mkhabela et al., 2011) has allowed for the development of frequent NDVI products over large areas. In particular, the daily revisit capability of MODIS (resulting in 8 - 16 day composite products), has made its data a common choice for crop phenology studies and monitoring systems on regional or country-wide scales (Begue et al., 2014; Bolton and Fried1, 2013; Chen et al., 2012; Fangping et al., 2007; Ganguly et al., 2010; Liang et al., 2004; Mkhabela et al., 2011; Ren et al., 2008; Son et al., 2014; Zhang et al., 2015; Zhang et al., 2003). However, the limitation of these products is their coarse spatial resolution (MODIS - 250 to $500 \mathrm{~m}$ and AVHRR - $1.09 \mathrm{~km}$ at nadir), making them incapable of detecting variability at fine scales because of mixed pixel effects whereby a single pixel in the image may cover two or more fields or management units (Peng et al., 2011; Xiao et al., 2005). Hence, there is limited capacity to use this data to provide crop growth information at the localised scale that is appropriate to farmers.

Field sizes in China are commonly less than 1ha, so high spatial resolution information is important to for assessing crop performance and influencing farmer decision making. Landsat provides images at a finer spatial resolution of $30 \mathrm{~m}$ and several studies have constructed NDVI 
time-series using multi-temporal Landsat imagery with the aim of investigating crop phenology (Maxwell and Sylvester, 2012; Qiu et al., 2015). However, Landsat is somewhat limited by the longer revisit time of 16 days and individual Landsat scenes can be contaminated by cloud cover and cloud shadow which can substantially increase the time between useable images to 32 days or more. Hence, the lower temporal resolution of Landsat data can mean that critical stages during the crop phenological cycle are under-sampled.

With advances in computer processing power, it has been possible to develop spatio-temporal fusion approaches to blend fine temporal, coarse spatial resolution satellite imagery (such as provided by MODIS) with coarse temporal, fine spatial resolution data (such as Landsat images). These fusion approaches generate downscaled fine temporal and fine spatial resolution data and several methods have been developed over the last decade to achieve this. Most notably, Gao et al. (2006) proposed a Spatial and Temporal Adaptive Reflectance Fusion Model (STARFM) to fuse Landsat and MODIS data. To improve the performance of STARFM for heterogeneous landscapes, an enhanced STARFM (ESTARFM) was developed by Zhu et al. (2010). For mapping forest disturbance, STARFM was extended with a spatial and temporal adaptive algorithm for mapping reflectance change (Hilker et al., 2009). Huang and Song (2012) applied a sparse representation to characterise the relationship between structures in known fine spatial resolution Landsat images and corresponding coarse spatial resolution MODIS images, and the unknown fine spatial resolution image was reconstructed through sparse coding. Song and Huang (2013) super-resolved a coarse spatial resolution MODIS image with sparse representation first, which was then fused with a known Landsat image by high-pass modulation to obtain a Landsat-like image on the prediction date. While several studies have demonstrated value of spatial fusion techniques in generating high spatio-temporal resolution images in various applications (Chen et al., 2015; Huang et al., 2013; Zhang et al., 2014a; Zhang et al., 2014b; Zhu et al., 2010), there has been limited research to explore the applicability of fine spatio-temporal data for characterising rice crop phenology. Yet, fine spatio-temporal information on rice growth and comparisons of crop performance at a field level could be of great benefit to farmers, researchers and extension workers.

The Science and Technology Backyard (STB) programme was initiated by China Agricultural University to work with farmers at village level to develop, test and spread best practice using the concept of 'Double High Technologies' (high productivity and high efficiency) to achieve food security and environmental sustainability (Shen et al., 2013). Whilst highly successful at the sites where it has been implemented (Zhang et al., 2016), this initiative is currently limited in the impact it can make due to the vast scale of agriculture in China. Within this context, satellite remote sensing has the potential to provide crop growth information that can provide a means of extending the STB programme out to farmers and other stakeholders across a range of spatial scales. This study used an STB site in Heilongjiang province in northeast China to assess the potential for characterising paddy rice crop phenology using remotely-sensed data at high spatio-temporal resolution. The key objectives of the study were to: (i) develop a suitable image processing workflow which generates downscaled MODIS NDVI time-series data at 30m spatial resolution every 8-days during the rice crop growing season; (ii) use the downscaled MODIS NDVI data to construct phenology curves for individual rice fields, (iii) use the curves to extract crop seasonality parameters in order to assess inter-annual variability in crop growth across the study region; (iv) demonstrate how these data can be used to quantify the variability in crop performance between and within fields.

\section{Materials and methods}

\subsection{Study site}


The study was conducted at an STB site in the town of Jiansanjiang, Heilongjiang province, northeast China (longitude $132^{\circ} 43^{\prime} 22.7^{\prime \prime} \mathrm{E}$ and latitude $47^{\circ} 13^{\prime} 06.2^{\prime \prime} \mathrm{N}$ ). The STB site is comprised of 186 fields (total area of $33.5 \mathrm{~km}^{2}$ ), 63 of which are used for paddy rice farming $\left(11.7 \mathrm{~km}^{2}\right)$ (Figure 1). This area was chosen as it is typical of the type of mechanised agriculture the is responsible for the majority of rice production in China. The area is characterised by a sub-humid continental monsoon climate with a warm summer and cold winter (Gnyp et al., 2014). The mean annual temperature amounts to $2^{\circ} \mathrm{C}$ while the mean annual precipitation is $550 \mathrm{~mm}$ (Wang and Yang, 2001). Records show that $70 \%$ of the precipitation occurs between the months of June and September in the study area (Gnyp et al., 2014). Xing et al. (1994) noted that the dominant soil type within Heilongjiang is the Albic soil, which is classified as mollic planosols and Typical Argialbolls according to the soil taxonomy specified in the FAOUNESCO system. Generally, the top layer of the soil is thin (ranging between $10-25 \mathrm{~cm}$ ) and low in nutrients. The albic layer below the surface layer is compact and impermeable (Yuan et al., 2006).

The main crops in the region include soybean, corn, wheat and paddy rice (which according to Liu et al.(2014) accounts for $15.5 \%$ of crop land in the region in 2010). The area around Jiansanjiang is dominated by paddy rice fields which are transplanted in April and harvested in October. Fields are irrigated and under water from April through to July. The fields tend to be frozen over winter.

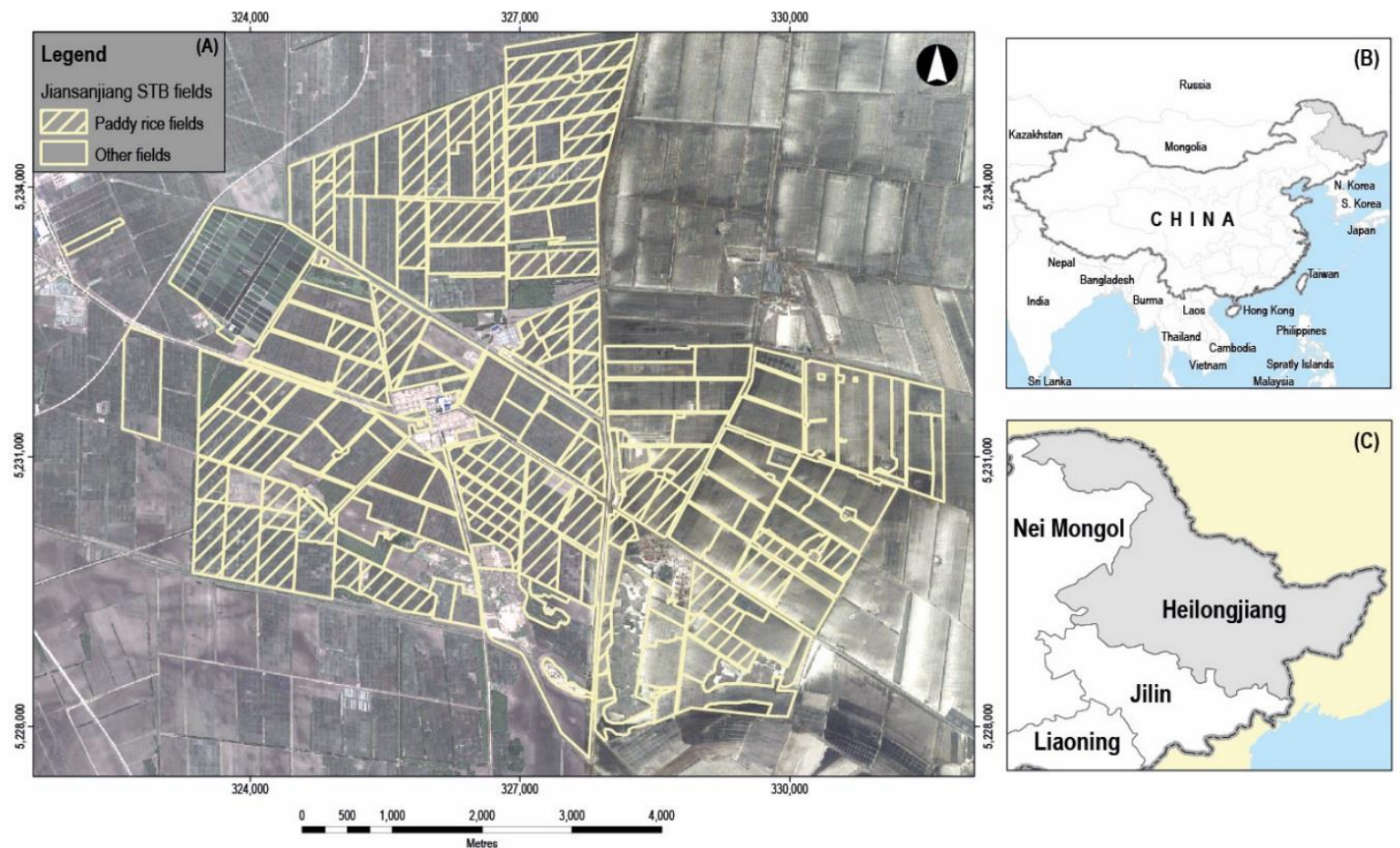

Figure 1. Map of study area showing (A) Jiansanjiang Science and Technology Backyard fields(Background image source: "Jiansanjiang STB field, Heilongjiang province, northeast China" 47²13'06.2” N, 132 43’22.7” E. Google Earth 4 March 2015); (B) Heilongiiang province and (C) geographical boundary of China.

\section{2. $\quad$ Rice crop growth data}

Based on existing literature (Fan et al., 2011; IRRI, 2016; Mosleh et al., 2015) the growth of rice crops have been categorised into three stages: the vegetative, reproductive, and ripening stages. The vegetative stage (approximately 65 days) consists of transplantation, tillering and stem elongation phases. The reproductive stage (approximately 30-35 days) consists of panicle 
initiation, booting / heading and flowering phases. The ripening stage (approximately 30 days) consists of milk, dough and mature phases, and an additional 18 days is typically included for harvesting. Records of growth dates for paddy rice fields in Jiansanjiang STB experimental site are presented in table 1 . 
Table 1 Records of rice crop growth dates for Jiansanjiang STB experimental site

\begin{tabular}{lll}
\hline Stages & Phases & Date range \\
\hline & Pre-transplanting / flooding & April 15- May 10 \\
\hline Vegetative & Transplanting & May 10 - May 25 \\
& Tillering & June $1-$ June 20 \\
& Stem elongation & June 21 - June 25 \\
\hline Reproductive & Panicle initiation & June 28 - July 15 \\
& Heading & July 15 - August 1 \\
& Flowering & August $1-$ August 10 \\
\hline Ripening & Milking & August $10-$ September 10 \\
& Dough & September 10 - September 20 \\
& Mature grain & September 20 - October 10 \\
\hline
\end{tabular}

\subsection{Acquisition and processing of remotely sensed data}

The remotely sensed data used in the study included multi-temporal Landsat (i.e. Landsat Enhanced Thematic Mapper Plus - ETM+ and Landsat 8 Operational Land Imager - OLI) and MODIS (MOD09Q1) surface reflectance products. Both Landsat and MODIS data were downloaded from the United States Geological Survey (USGS) Earth Explorer website (http://earthexplorer.usgs.gov). Figure 2 presents the overall workflow developed in this study for processing and analysing the Landsat and MODIS data.

\subsubsection{Landsat data acquisition and pre-processing}

The Landsat images covering the study area had Worldwide Reference System (WRS) 2 address path 114 and row 27. During image selection, it was important to ensure that all scenes were free of clouds, cloud shadows or snow. Cloud contamination has shown to be a major issue during the rice growing season, obscuring paddy fields and consequently underestimating corresponding NDVI values ( $\mathrm{Li}$ et al., 2016). To ensure accurate estimates of NDVI are calculated, all cloud contaminated images were excluded from the analysis. Details of the dates of acquisition of the Landsat images used in this study are presented in Table 2 and these represent all available cloud free images for the years 2014 and 2015 for the study area.

Table 2 Acquisition dates (2014 and 2015) of Landsat satellite imagery used in study (L7 - Landsat 7 and L8 - Landsat 8).

\begin{tabular}{lccccccccc}
\hline Image & April & May & June & July & August & September & October & November & Year \\
\hline L7 ETM+ & $22^{\text {nd }}$ & - & - & - & - & - & - & - & 2014 \\
L8 OLI & - & - & 1 st & 3 rd & 20 th & 21 st & 23 rd & 8 th & 2014 \\
L7 ETM+ & - & - & - & - & 15 th & - & - & - & 2015 \\
L8 OLI & $1^{\text {st }}$ & - & 4 th & 22 nd & - & 8 th & 26 th & 11 th & 2015 \\
\hline
\end{tabular}

The Landsat image pre-processing stages included atmospheric correction, geometric correction of misaligned scenes, gap filling of Landsat 7 ETM+ images affected by failed Scan Line Correctors (SLC) and image sub-setting to include the study area (Figure 2). The Landsat images were atmospherically corrected to ensure that they represented an absolute surface reflectance product and therefore could be used to derive time-series data that represented changes in surface reflectance without the influence of changes in atmospheric conditions. This correction was performed using the atmospheric correction module Fast Line-of-sight Atmospheric Analysis of Spectral Hypercubes (FLAASH) in ENVI (ENVI, 2009). The FLAASH module is capable of correcting all wavebands of Landsat from the visible through to thermal. Geometric correction of any misaligned Landsat images was performed using the polynomial geometric model in ERDAS Imagine software (ERDAS, 2014). The process of gap 
filling for Landsat 7 ETM+ images with SLC-off was performed using the Landsat Gap fill module available in ENVI 4.7 (Yale Center for Earth Observation, 2013). For this procedure, the Single file gap fill (triangulation) option was used to fill existing line gaps in each Landsat scene. This technique uses a linear transformation that adjusts the image based on mean and standard deviation values of each band contained in the scene (Scaramuzza et al., 2004).

\subsubsection{MODIS data acquisition and pre-processing}

The standard MODIS gridded products are organised in a tile system using a sinusoidal projection, each covering an area of $1200 \mathrm{~km}$ x $1200 \mathrm{~km}$ (approximately $10^{\circ}$ latitude by $10^{\circ}$ longitude at the equator). The study area overlaps two tiles (H26V04 and H27V04), data from both of which were downloaded for this study. The downloaded MODIS data covered 2014 and 2015 and for each year there were 46 images (Days 1 - 361, at 8-day intervals). For this study, the MODIS Surface Reflectance dataset was used to generate the MODIS NDVI timeseries. The MODIS Surface Reflectance products provide an estimate of the surface spectral reflectance comparable to measurements at ground level void of atmospheric scattering or absorption. The MODO9Q1 product that was used in this study has two bands (band 1: 620 $670 \mathrm{~nm}$ (red) and band 2: $841-876 \mathrm{~nm}$ (near infrared)), 250m spatial resolution and is comprised of 8-day gridded level-2 (L2G) data. Each pixel of the MOD09Q1 dataset contains the best possible L2G observation during an 8-day period and is usually selected based on highobservation coverage, low-view angle, absence of clouds or cloud shadow, and aerosol loading (USGS, 2016). This version of the MODIS Surface Reflectance product has been assessed over a widely distributed set of locations and time periods through a number of ground truth and validation efforts (USGS, 2016). The downloaded MODIS products were subsequently exported and re-projected to the Universal Traverse Mercator (UTM) Zone 53 North (datum World Geodetic System 1984), to match the Landsat images. 


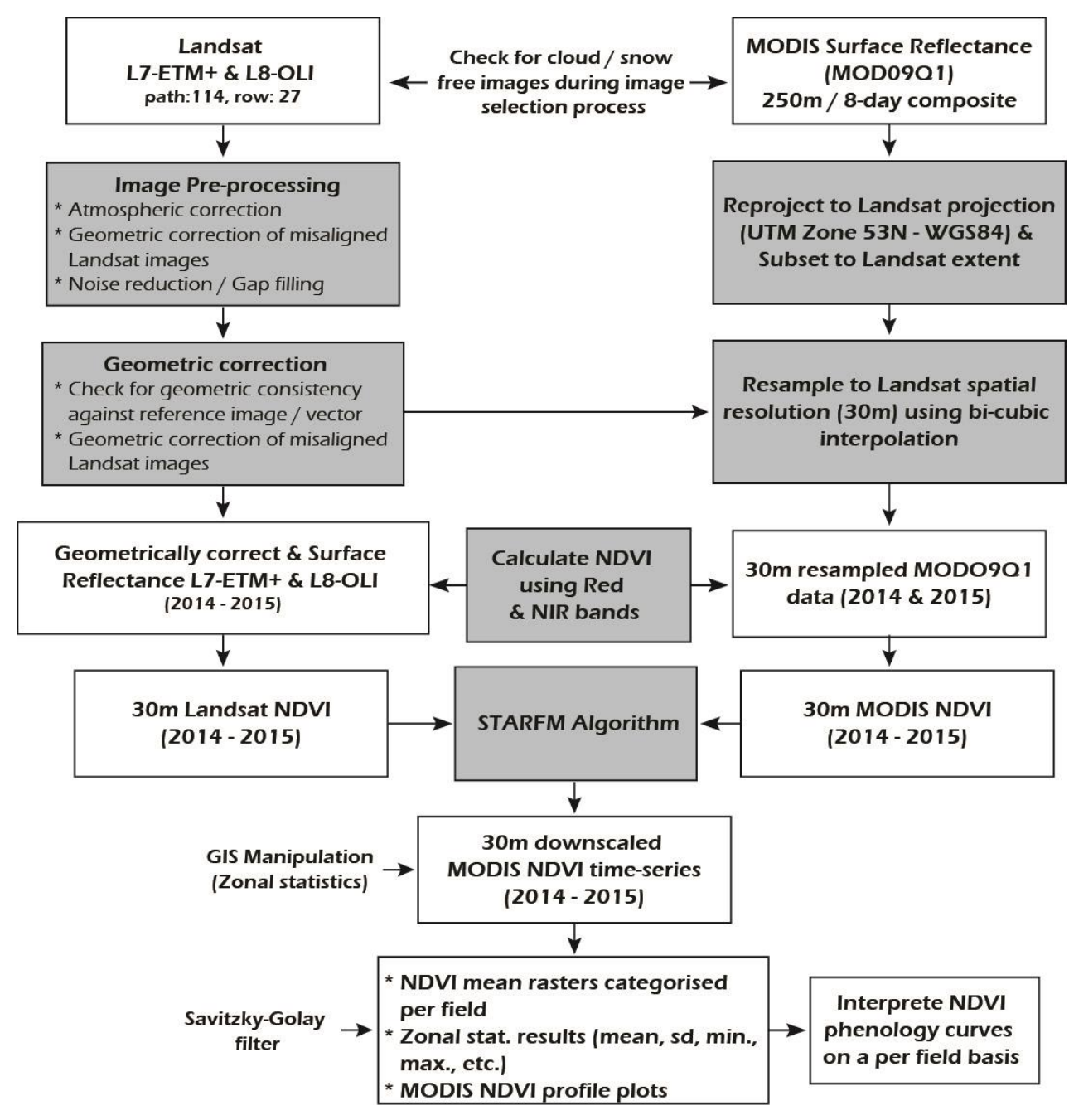

Figure 2. The workflow for processing and analysis of the Landsat and MODIS data.

\subsection{MODIS NDVI downscaling procedure}

For each of the Landsat and MODIS scenes that were pre-processed, NDVI images were derived using:

$$
N D V I=\frac{\rho_{N I R}-\rho_{R E D}}{\rho_{N I R}+\rho_{R E D}}
$$

where $\rho_{N I R}$ and $\rho_{R E D}$ are the surface reflectance values in the near-infrared and red bands, respectively.

A bilinear interpolation was applied to each 250m MODIS NDVI image and resampled to a spatial resolution of $30 \mathrm{~m}$ (same as the Landsat-NDVI data). The 30m MODIS and Landsat NDVI images were subsequently used as inputs for the STARFM algorithm for downscaling the MODIS NDVI data to generate a time-series of 30m NDVI data at an 8-day interval for both 2014 and 2015. The principle of the STARFM approach is briefly introduced as follows. For a given time $t_{0}$, the Landsat-like image $L\left(x, y, t_{0}\right)$ is estimated as

$$
L\left(x_{w / 2}, y_{w / 2}, t_{0}\right)=\sum_{i=1}^{w} \sum_{j=1}^{w} \sum_{k=1}^{n} W_{i j k}\left(M\left(x_{i}, y_{j}, t_{0}\right)+L\left(x_{i}, y_{j}, t_{k}\right)-M\left(x_{i}, y_{j}, t_{k}\right)\right)
$$


where $w$ is the size of spatially neighboring window, $n$ is the size of temporally neighboring window, $M$ means MODIS data, $L$ means Landsat data, and $W$ is the weight related to the difference between MODIS images, to the difference between corresponding MODIS and Landsat images, and to spatial distance. Further details on the approach can be found in Gao et al.(2006). The 30m downscaled(d)MODIS NDVI images were also checked for geometric consistency against a georectified Landsat image of the study area.

\subsection{Validation of dMODIS NDVI data}

The dMODIS NDVI output for both years (2014 and 2015) was validated using independently calculated Landsat NDVI images. A linear regression was conducted using mean values of NDVI from the downscaled and reference images for all rice fields at the study site, using image dates that were most closely matched (see Table 3 ). Hence, a total of 441 data points representing mean NDVI per paddy rice field were analysed.

Table 3 Julian days of corresponding Landsat and dMODIS NDVI results

\begin{tabular}{llccccccc}
\hline Year & NDVI Measure & \multicolumn{7}{c}{ Julian Dates } \\
\hline 2014 & Landsat NDVI & 112 & 152 & 184 & 232 & 264 & 296 & 312 \\
2014 & dMODIS NDVI & 113 & 153 & 185 & 233 & 265 & 297 & 313 \\
\hline 2015 & Landsat NDVI & 91 & 155 & 203 & 227 & 251 & 299 & 315 \\
2015 & dMODIS NDVI & 89 & 153 & 201 & 225 & 249 & 297 & 313 \\
\hline
\end{tabular}

\subsection{Generating NDVI time-series for individual fields}

The process of generating NDVI variables for multi-temporal dMODIS NDVI images was performed with ArcGIS Model builder (ESRI, 2014). The key model parameters used in executing this model were the dMODIS NDVI images and vector boundary shapefiles defining STB fields which had previously been manually digitised from very high resolution RapidEye satellite data acquired in 2014. Figure 3 presents the customised ArcGIS schematics developed in the study. Zonal statistics analysis was used to generate statistical measures of NDVI (mean, standard deviation, minimum and maximum) from the image pixels contained within each field, for each of the multi-temporal NDVI images. The NDVI statistics for each field were stored in both raster and tabular formats in a geodatabase and used in further analysis. For the subsequent analysis that is reported in this paper, the values of mean NDVI per field were used to generate NDVI time-series profiles for each field in 2014 and 2015. 


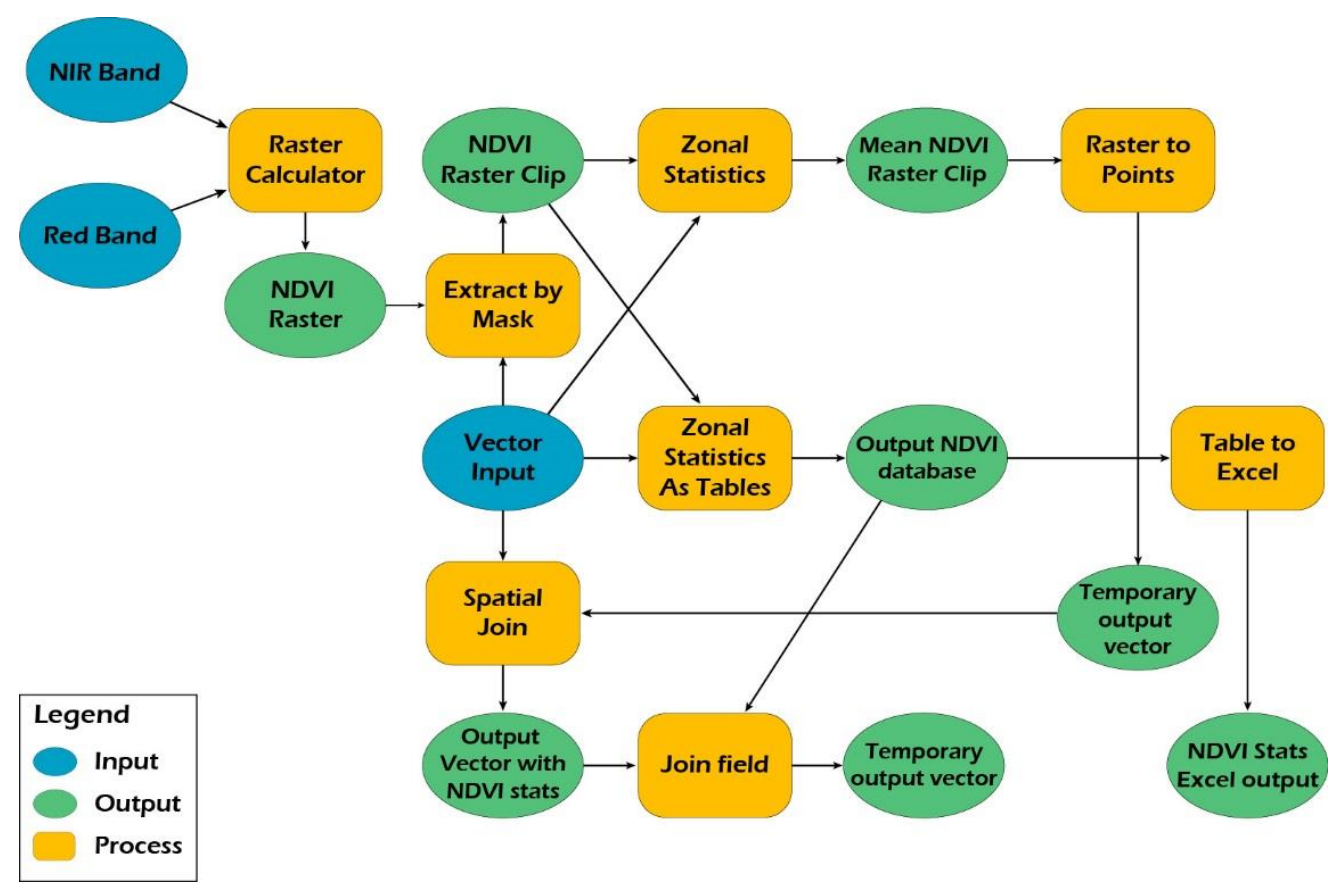

Figure 3. Schematics of customised model developed using ArcGIS for zonal statistics analysis. 


\section{7. $\quad$ Noise reduction in NDVI time series}

Despite pre-processing efforts time-series remotely sensed data can contain some noise due to factors such as residual atmospheric effects and variations in sun-sensor-surface viewing geometries. In order to reduce the amount of noise contained within the dMODIS NDVI timeseries for each rice field the Savitzky-Golay (S-G) filter was used. The S-G filter (also known as the least squares or digital smoothing polynomial) has previously been shown to be an effective means of reducing noise in remotely-sensed vegetation index time-series (Chen et al., 2004; Pan et al., 2015; Savitzky and Golay, 1964; Schafer, 2011). In this study the S-G filter was applied to the dMODIS NDVI time-series using the statistical programming language $\mathrm{R}$ (The R Core Team, 2014). The resulting filtered dMODIS NDVI time-series were then used to represent the phenology of the rice crop in each field in the subsequent analysis.

\subsection{Extraction of crop seasonality parameters from dMODIS NDVI time-series}

The phenology curve for each field was used to extract key crop seasonality parameters for 2014 and 2015. For this study the seasonality parameters investigated included: the green-up date, peak of reproductive growth period, harvesting date, and duration of growth period (from green-up date to harvesting). The approach for deriving these parameters was based on previous studies that have analysed NDVI time series (Li et al., 2016; Pan et al., 2015).

\section{Results and discussion}

\subsection{Validation of downscaled MODIS NDVI time-series}

Figure 4 shows the results of the validation process performed using the dMODIS NDVI and independent Landsat NDVI data, indicating a close correspondence $\left(\mathrm{R}^{2}=0.93\right.$ and 0.84 for 2014 and 2015, respectively. This demonstrated that the dMODIS NDVI was appropriate for the subsequent analysis. Figure 5 presents an example of the dMODIS NDVI images generated from the original Landsat and MODIS NDVI inputs using the STARFM algorithm.

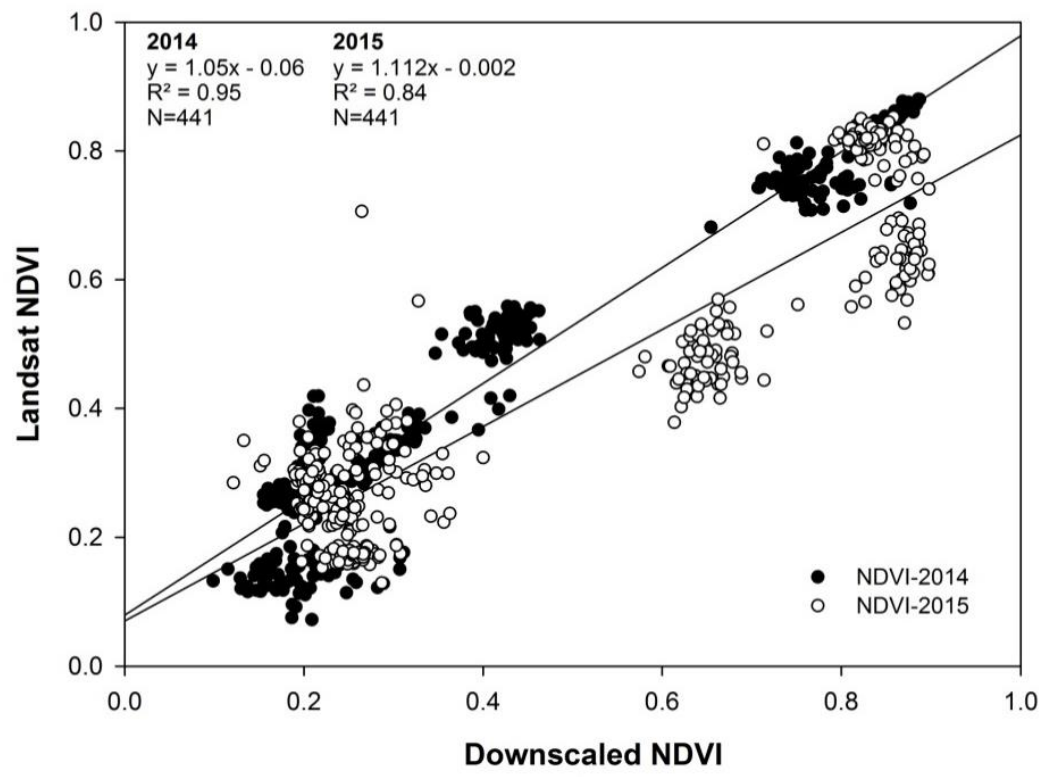

Figure 4. Scatter plot and regression results between Landsat derived NDVI and down-scaled MODIS NDVI outputs. 


\subsection{Interpreting the phenology curves derived from dMODIS NDVI time-series}

The phenology curves for all 63 STB fields in 2014 and 2015 are displayed in Figure 6, based on the dMODIS NDVI time-series values. The lowest NDVI values were recorded during the pre-planting and flooding stage (i.e. April 15 to May 10, DOY 105-129) when values were well below 0.3 tending to negative. This concurs with previous observations of low NDVI values being generated by bare soil or waterlogged fields in the pre-planting and flooding phase (Li et al., 2016). After the pre-planting stage, NDVI values in both years experienced a rapid increase that is characteristic of the vegetative phase. The rapid increase of NDVI values in June (day $150-180$ ) is a characteristic of the stem elongation phase which usually generates complete closure of the rice plant canopies. The highest NDVI values were consistently acheived during the panicle initiation and heading phases of the reproductive stage. During the 2014 growing season, peak NDVI values of between 0.89 and 1.0 were observed during the panicle initiation and heading phases. Whereas in 2015 the peak NDVI values ranged between 0.89 and 0.91 for the STB rice fields. Once the rice plants developed into the ripening phase (i.e. milk, dough and mature stages), the leaves gradually undergo chlorosis with some deterioration in canopy structure. Hence, for both years analysed the NDVI values during this phase declined rapidly towards values of $0.2-0.3$. These results are consistent with those of Shibayama and Akiyama (1989) who observed that peak NDVI values were obtained in the reproductive stage followed by a decline during the ripening stages resulting from withering of leaves in the rice canopy. As Figure 6 shows, NDVI values continued to decrease further during the post-harvest phase eventually reaching the levels observed during the original pre-planting stage. In a previous study, Li et al. (2016) observed that post-harvest paddy rice fields are comprised mainly of residual rice plants and exposed soils with very low NDVI responses, a similar trend observed in this study.

These results demonstrate the value of the downscaling process utilised in this study, which has generated high spatial and temporal resolution NDVI data. This has enabled the production of NDVI time series for individual fields which have sufficient sampling frequency to capture the detail of the phenological cycle. As Figure 6 demonstrates there is considerable variation in phenology between individual fields which, given that the general environmental conditions are similar across the study site, reflect local variations in soil and hydrological conditions and the crop husbandry regimes within each field. Such data therefore begin to form indicators of crop performance that can be used to guide subsequent strategic and tactical management interventions. 

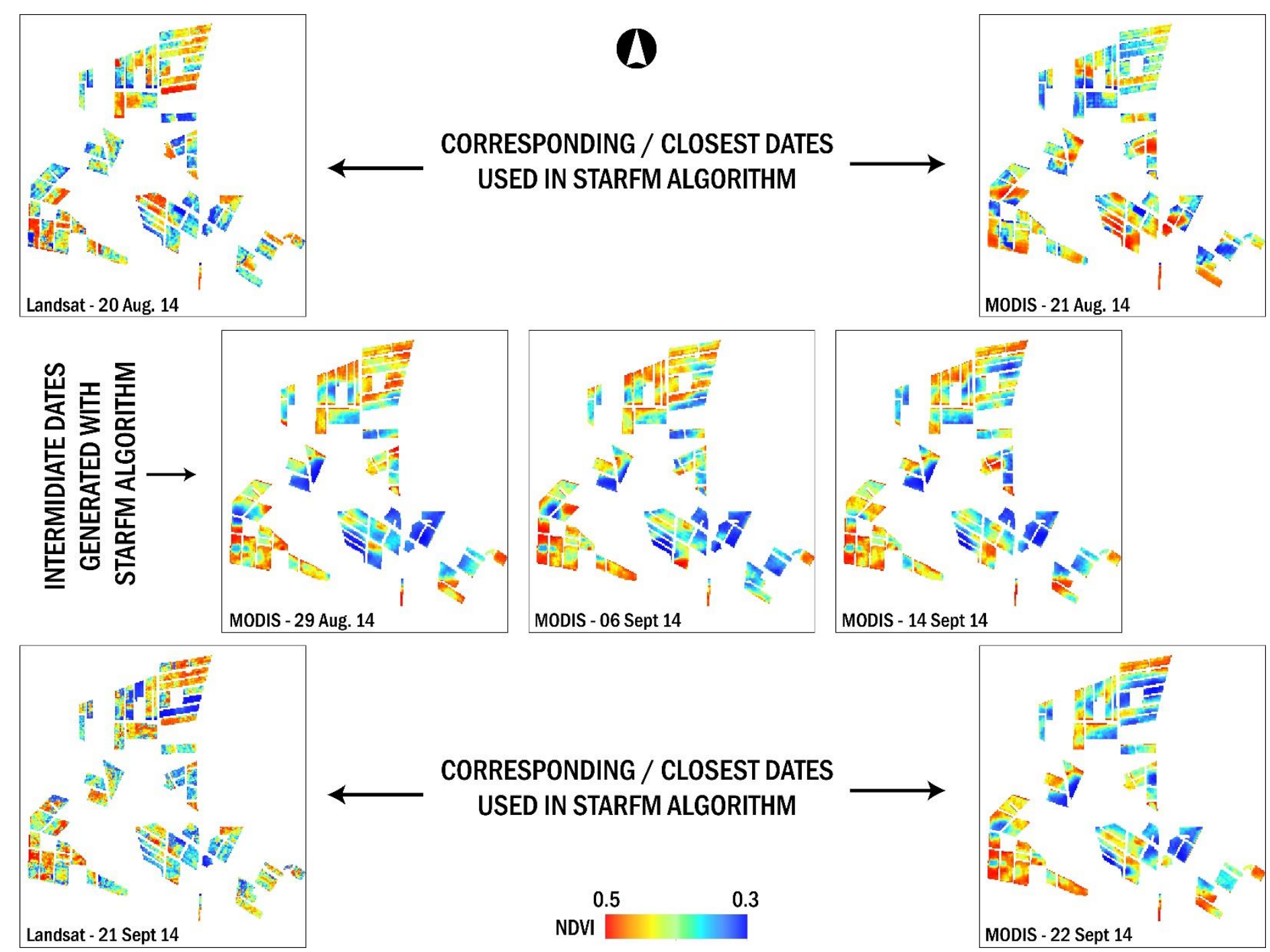

CORRESPONDING / CLOSEST DATES

USED IN STARFM ALGORITHM

0.5

NDVI
0.3

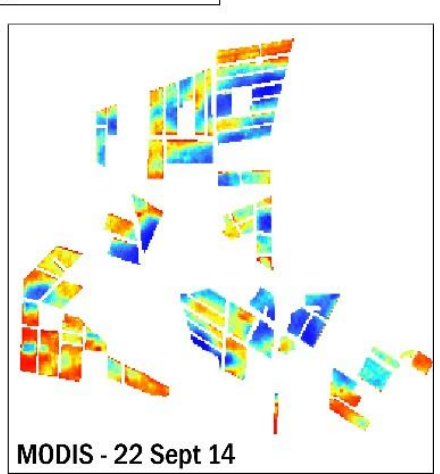


Figure 5 An example of Landsat and MODIS NDVI images used for the downscaling process in STARFM for the Jiansanjiang STB rice fields. The corresponding/closest Landsat and MODIS NDVI image pairs were used in the STARFM algorithm to generate 30m downscaled MODIS NDVI images at 8 day intervals. 


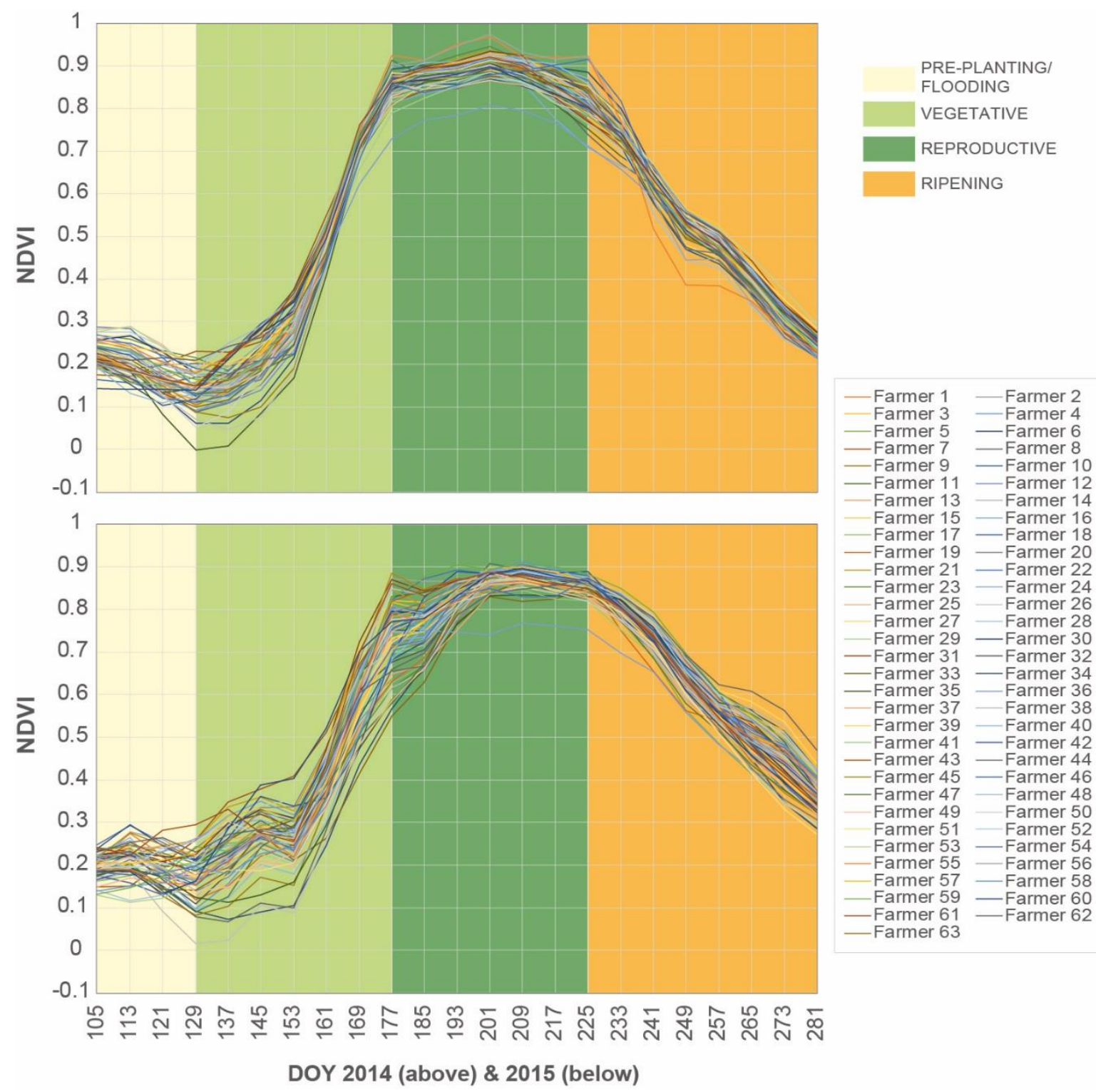

Figure 6. Phenology curves over pre-planting / flooding, vegetative, reproductive and ripening stages generated with dMODIS NDVI values for all 63 STB rice fields for 2014 and 2015.

\subsection{Extraction of seasonality parameters}

Figure 7 presents the overall phenological profile of the rice crop across the study site for the 2014 and 2015 growing seasons, based on mean values of dMODIS NDVI data across all STB fields on each sampling occasion. Based on these overall phenology curves the crop seasonality parameters were determined. The green-up dates of the rice crop in 2014 and 2015 were identified as days 137 and 129, respectively (Figure 7), both with NDVI values lower than 0.2. This was followed by a gradual increase in NDVI curve till maximum values, representing the peak of the reproductive stage, are attained. The highest NDVI values for 2015 (day 209, July 28) came much earlier than in the previous year (day 233, August 21), indicating that the maximum extent of canopy development occurred during the heading and late flowering stages, respectively. After this, NDVI started to fall off slightly in late August (2015) and early September (2014), before declining rapidly as the crop started to senesce (Figure 7). NDVI continued to fall until harvest in late October for both years (day 281 in 2014 and 297 in 2015). The duration of the growth period for rice crops in the study area was 160 days in 2014 and 152 days in 2015. 
Overall, the results showed distinct inter-annual differences in the rice crop seasonality parameters. These findings are only possible because of the use of the high spatio-temporal NDVI time-series as such phenological differences would be difficult to identify with data of lower spatial resolution such as MODIS, where the large pixels may cover several fields containing different crop types. Likewise, these inter-annual crop seasonality differences would be difficult to identify with data of lower temporal resolution such as Landsat as the differences in dates for many seasonality parameters are less than the revisit time of the sensor. As has been demonstrated in previous work the precise determination of seasonality parameters identified here can be used for numerous applications such as in crop yield modelling (Bouman, 2001; Peng et al., 2004), estimating net primary production (Kimball et al., 2004), and quantifying crop water requirements (Dingkuhn and Le Gal, 1996; Pandey et al., 2014). Hence, the techniques developed in this study have potential to make a valuable contribution to several areas of the science and agronomy of rice production.

Figure 8 shows the spatial variability of NDVI values across each of the paddy rice fields on each of the dates that define the rice crop seasonality parameters in 2014 and 2015. This demonstrates that while many crop areas are at the same level of canopy development on each of these occasions, there is still considerable variability between and within fields. These findings highlight the disparities in crop performance between the site or regional norm and that of each field or part-field. By observing such disparities over multiple growing seasons it is possible consistently under-performing locations, which may be attributed to specific environmental challenges in crop production or sites where crop management practices are less effective than in neighbouring fields or part-fields. Hence, again, this demonstrates the value of the high spatio-temporal NDVI time-series data developed in this study. Such data permits the acquisition of crop performance information at appropriate scales to guide individual farmer decision-making, but at the same time offers the opportunity of deriving such information across a wide spatial area covered by an entire Landsat or MODIS scene (as determined by the availability of suitable imagery of either type), which is effective for broader food security management and agricultural policy development. 


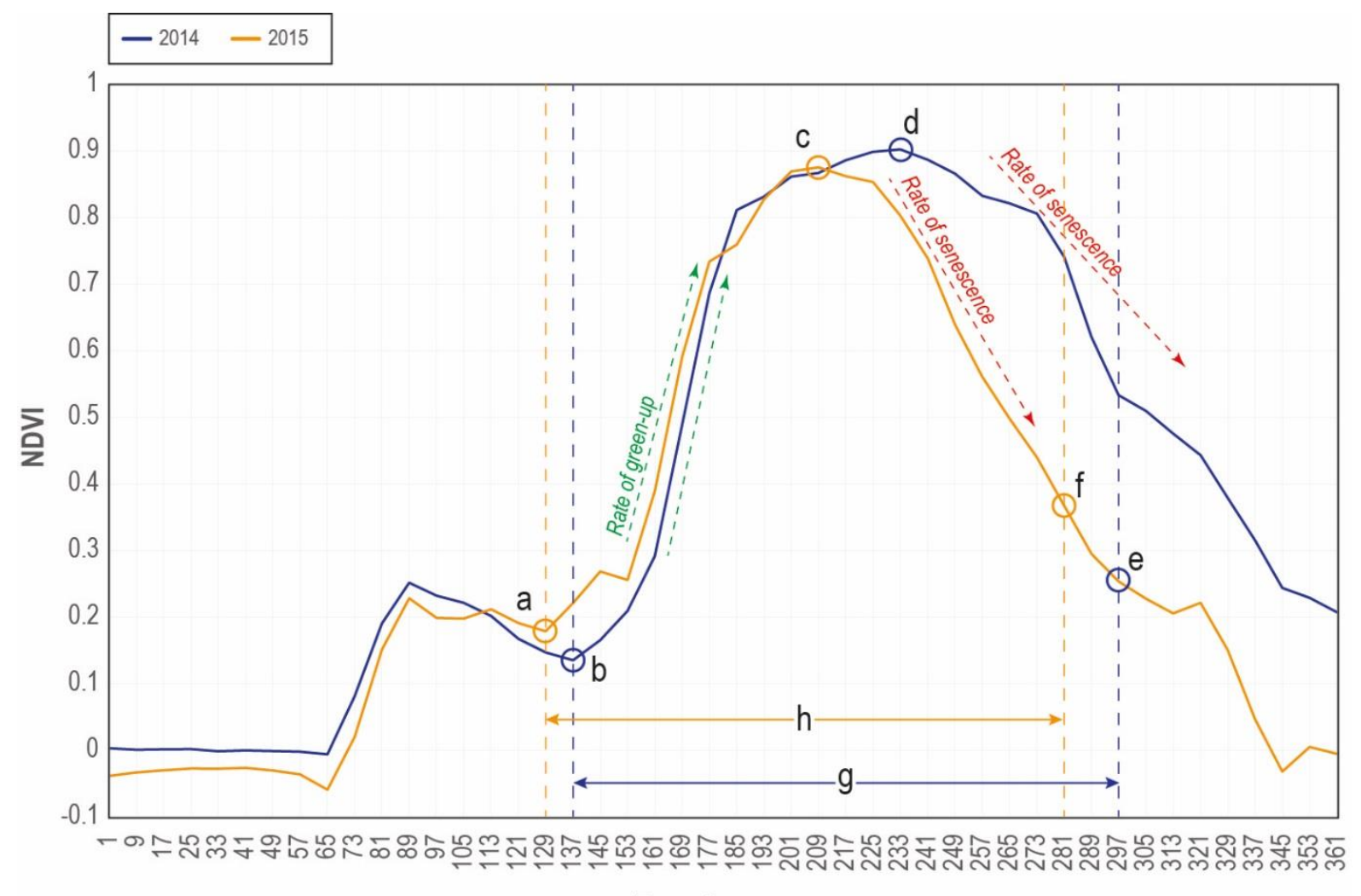

Day of year

Figure 7. Seasonality parameters of rice crops in the study area showing the following: green-up dates for (a) 2015 and (b) 2014; maximum NDVI dates depicting peak reproductive growth phase for (c) 2015 and (d) 2014; harvest date of rice crops for (e) 2014 and (f) 2015; and length of growth duration for (g) 2015 and (h) 2014. 


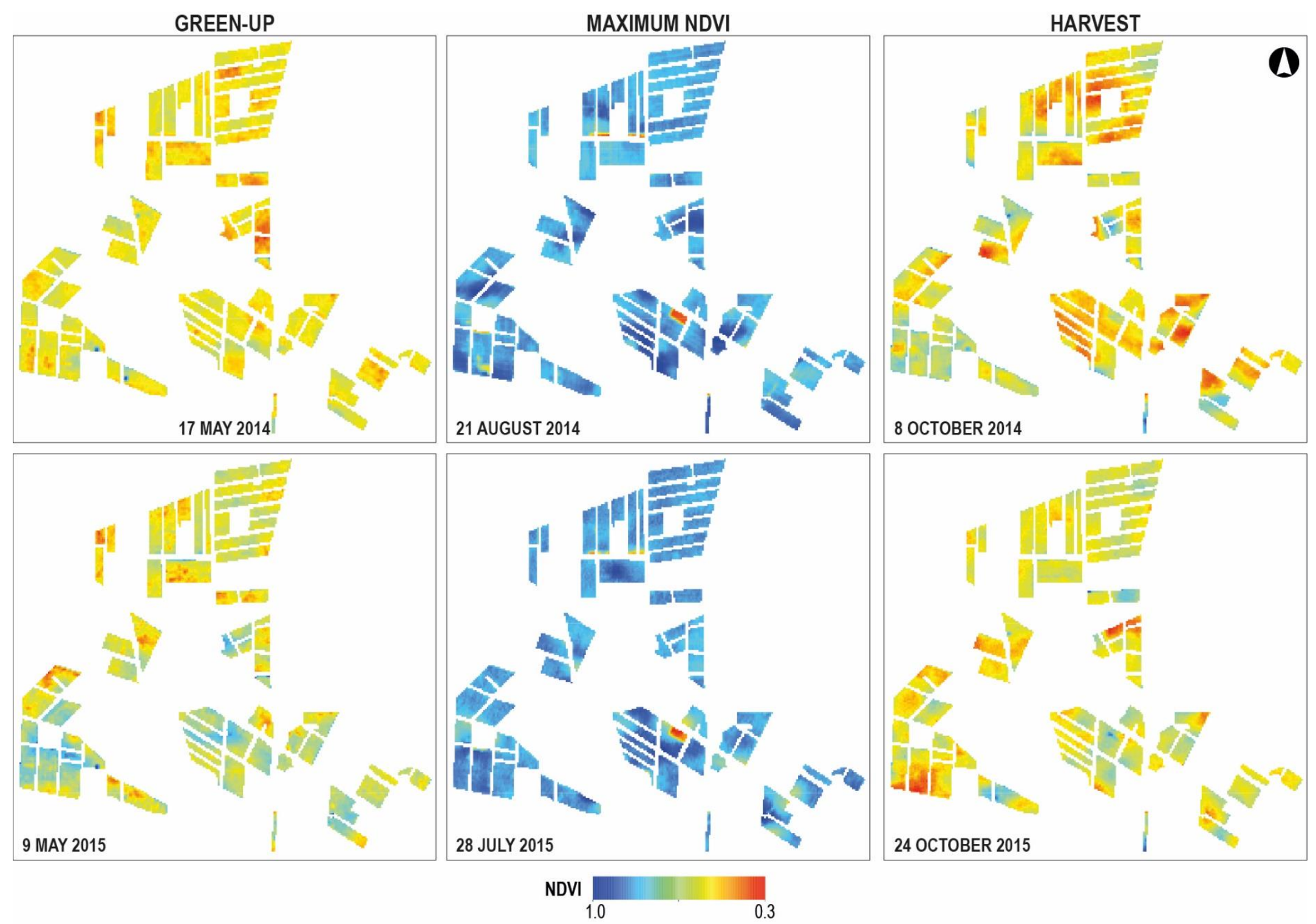

Figure 8. Downscaled MODIS NDVI images at the dates of the key seasonality parameters of the rice crop for 2014 and 2015. 


\section{Conclusion}

This study developed an image processing workflow which fused Landsat and MODIS images to generate a high spatio-temporal resolution NDVI dataset and used this to generate phenology curves for individual rice fields. These data permitted the extraction of key crop seasonality parameters that quantified inter-annual growth variability for a whole agricultural region and enabled the mapping of variability in crop performance between and within rice fields. Hence, this methodology can provide rice crop growth data that is suitable for informing agronomic policy and practice across a wide range of scales. Moreover, this technique has the potential to be translated to other combinations of data from different satellite remote sensing systems and to different crop types. Therefore, this represents a generic approach which can provide a source of evidence with which to guide the process of sustainable agricultural intensification in China and other countries where the need to achieve food security and environmental sustainability is imperative.

\section{Acknowledgements}

The publication was made possible through funding from the UK Science \& Technology Facilities Council (STFC) Newton Agri-Tech Programme. The project is titled "Remote Sensing for Sustainable Intensification in China through Improved Farm Decision-Making." 


\section{References}

Begue, A., Vintrou, E., Saad, A., Hiernaux, P., 2014. Differences between cropland and rangeland MODIS phenology (start-of-season) in Mali. International Journal of Applied Earth Observation and Geoinformation 31, 167-170.

Bolton, D.K., Friedl, M.A., 2013. Forecasting crop yield using remotely sensed vegetation indices and crop phenology metrics. Agricultural and Forest Meteorology 173, 74-84.

Bouman, B., 2001. ORYZA2000: modeling lowland rice. IRRI.

Chen, B., Huang, B., Xu, B., 2015. Fine Land Cover Classification Using Daily Synthetic Landsat-Like Images at 15-m Resolution. IEEE Geoscience and Remote Sensing Letters 12, 2359-2363.

Chen, C., Son, N., Chang, L., 2012. Monitoring of rice cropping intensity in the upper Mekong Delta, Vietnam using time-series MODIS data. Advances in Space Research 49, 292-301.

Chen, J., Jönsson, P., Tamura, M., Gu, Z., Matsushita, B., Eklundh, L., 2004. A simple method for reconstructing a high-quality NDVI time-series data set based on the Savitzky-Golay filter. Remote sensing of Environment 91, 332-344.

Dingkuhn, M., Le Gal, P.-Y., 1996. Effect of drainage date on yield and dry matter partitioning in irrigated rice. Field Crops Research 46, 117-126.

Edlinger, J., Conrad, C., Lamers, J., Khasankhanova, G., Koellner, T., 2012. Reconstructing the spatiotemporal development of irrigation systems in Uzbekistan using Landsat time series. Remote Sensing 4, 3972-3994.

Elmore, A.J., Mustard, J.F., Manning, S.J., Lobell, D.B., 2000. Quantifying Vegetation Change in Semiarid Environments: Precision and Accuracy of Spectral Mixture Analysis and the Normalized Difference Vegetation Index. Remote Sensing of Environment 73, 87-102.

ENVI, 2009. Atmospheric Correction Module: QUAC and FLAASH User's Guide. ITT Visual Information Solutions, United States.

ERDAS, 2014. ERDAS Imagine 2014, 2014 ed. Hexagon Geospatial, Peachtree Corners Circle Norcross.

ESRI, 2014. ArcGIS Desktop: Release 10.2. Environmental Systems Research Institute, Redlands, CA. Fan, W., Chao, W., Hong, Z., Bo, Z., Yixian, T., 2011. Rice Crop Monitoring in South China With RADARSAT-2 Quad-Polarization SAR Data. Geoscience and Remote Sensing Letters, IEEE 8, 196200.

Fang, H., 1998. Rice crop area estimation of an administrative division in China using remote sensing data. International Journal of Remote Sensing 19, 3411-3419.

Fangping, D., Su, G., Liu, C., 2007. Seasonal variation of MODIS vegetation indexes and their statistical relationship with climate over the subtropic evergreen forest in Zhejiang, China. Geoscience and Remote Sensing Letters, IEEE 4, 236-240.

FAOSTAT, 2014. Statistical Database of the Food and Agricultural Organization of the United Nations. Forkuor, G., Conrad, C., Thiel, M., Landmann, T., Barry, B., 2015. Evaluating the sequential masking classification approach for improving crop discrimination in the Sudanian Savanna of West Africa. Computers and Electronics in Agriculture 118, 380-389.

Ganguly, S., Friedl, M.A., Tan, B., Zhang, X., Verma, M., 2010. Land surface phenology from MODIS: Characterization of the Collection 5 global land cover dynamics product. Remote Sensing of Environment 114, 1805-1816.

Gao, F., Masek, J., Schwaller, M., Hall, F., 2006. On the blending of the Landsat and MODIS surface reflectance: Predicting daily Landsat surface reflectance. Geoscience and Remote Sensing, IEEE Transactions on 44, 2207-2218.

Gnyp, M.L., Miao, Y., Yuan, F., Ustin, S.L., Yu, K., Yao, Y., Huang, S., Bareth, G., 2014. Hyperspectral canopy sensing of paddy rice aboveground biomass at different growth stages. Field Crops Research 155, 42-55.

Hilker, T., Wulder, M.A., Coops, N.C., Linke, J., McDermid, G., Masek, J.G., Gao, F., White, J.C., 2009. A new data fusion model for high spatial-and temporal-resolution mapping of forest disturbance based on Landsat and MODIS. Remote Sensing of Environment 113, 1613-1627.

Holben, B.N., Tucker, C.J., Fan, C.-J., 1980. Spectral assessment of soybean leaf area and leaf biomass. Huang, B., Song, H., 2012. Spatiotemporal reflectance fusion via sparse representation. IEEE Transactions on Geoscience and Remote Sensing 50, 3707-3716. 
Huang, B., Zhang, H., Song, H., Wang, J., Song, C., 2013. Unified fusion of remote-sensing imagery: generating simultaneously high-resolution synthetic spatial-temporal-spectral earth observations. Remote Sensing Letters 4, 561-569.

Huang, C., Goward, S.N., Masek, J.G., Thomas, N., Zhu, Z., Vogelmann, J.E., 2010. An automated approach for reconstructing recent forest disturbance history using dense Landsat time series stacks. Remote Sensing of Environment 114, 183-198.

Huete, A., Didan, K., Miura, T., Rodriguez, E.P., Gao, X., Ferreira, L.G., 2002. Overview ofthe radiometric and biophysical performance of the MODIS vegetation indices. remote sensing of environment 83, 195-213.

IRRI, 2016. Important management factors by growth stage. International Rice Research Institute (IRRI),

Ju, X., Liu, X., Zhang, F., Roelcke, M., 2004. Nitrogen fertilization, soil nitrate accumulation, and policy recommendations in several agricultural regions of China. AMBIO: a Journal of the Human Environment 33, 300-305.

Karkee, M., Steward, B.L., Tang, L., Aziz, S.A., 2009. Quantifying sub-pixel signature of paddy rice field using an artificial neural network. Computers and Electronics in Agriculture 65, 65-76.

Kastens, J.H., Kastens, T.L., Kastens, D.L.A., Price, K.P., Martinko, E.A., Lee, R.-Y., 2005. Image masking for crop yield forecasting using AVHRR NDVI time series imagery. Remote Sensing of Environment 99, 341-356.

Kimball, J.S., McDonald, K.C., Running, S.W., Frolking, S.E., 2004. Satellite radar remote sensing of seasonal growing seasons for boreal and subalpine evergreen forests. Remote Sensing of Environment 90, 243-258.

Kuenzer, C., Knauer, K., 2013. Remote sensing of rice crop areas. International Journal of Remote Sensing 34, 2101-2139.

Lenney, M.P., Woodcock, C.E., Collins, J.B., Hamdi, H., 1996. The status of agricultural lands in Egypt: The use of multitemporal NDVI features derived from landsat TM. Remote Sensing of Environment 56, 8-20.

Li, P., Feng, Z., Jiang, L., Liu, Y., Xiao, X., 2012. Changes in rice cropping systems in the Poyang Lake Region, China during 2004-2010. Journal of Geographical Sciences 22, 653-668.

Li, P., Jiang, L., Feng, Z., Sheldon, S., Xiao, X., 2016. Mapping rice cropping sy stems using Landsatderived Renormalized Index of Normalized Difference Vegetation Index (RNDVI) in the Poyang Lake Region, China. Frontiers of Earth Science 10, 303-314.

Liang, L., Schwartz, M.D., Fei, S., 2011. Validating satellite phenology through intensive ground observation and landscape scaling in a mixed seasonal forest. Remote Sensing of Environment 115, 143-157.

Liang, S., Fang, H., Hoogenboom, G., Teasdale, J., Cavigelli, M., 2004. Estimation of crop yield at the regional scale from MODIS observations, Geoscience and Remote Sensing Symposium, 2004. IGARSS'04. Proceedings. 2004 IEEE International. IEEE, pp. 1625-1628.

Liu, J., Kuang, W., Zhang, Z., Xu, X., Qin, Y., Ning, J., Zhou, W., Zhang, S., Li, R., Yan, C., 2014. Spatiotemporal characteristics, patterns, and causes of land-use changes in China since the late 1980s. Journal of Geographical Sciences 24, 195-210.

Maxwell, S.K., Sylvester, K.M., 2012. Identification of "ever-cropped" land (1984-2010) using Landsat annual maximum NDVI image composites: Southwestern Kansas case study. Remote sensing of environment 121, 186-195.

Mkhabela, M.S., Bullock, P., Raj, S., Wang, S., Yang, Y., 2011. Crop yield forecasting on the Canadian Prairies using MODIS NDVI data. Agricultural and Forest Meteorology 151, 385-393.

Mosleh, M.K., Hassan, Q.K., Chowdhury, E.H., 2015. Application of remote sensors in mapping rice area and forecasting its production: A review. Sensors 15, 769-791.

Pan, Z., Huang, J., Zhou, Q., Wang, L., Cheng, Y., Zhang, H., Blackburn, G.A., Yan, J., Liu, J., 2015. Mapping crop phenology using NDVI time-series derived from HJ-1 A/B data. International Journal of Applied Earth Observation and Geoinformation 34, 188-197.

Pandey, A., Kumar, A., Pandey, D., Thongbam, P., 2014. Rice quality under water stress. Indian Journal of Advances in Plant Research (IJAPR) 1, 23-26. 
Peng, D., Huete, A.R., Huang, J., Wang, F., Sun, H., 2011. Detection and estimation of mixed paddy rice cropping patterns with MODIS data. International Journal of Applied Earth Observation and Geoinformation 13, 13-23.

Peng, S., Huang, J., Sheehy, J.E., Laza, R.C., Visperas, R.M., Zhong, X., Centeno, G.S., Khush, G.S., Cassman, K.G., 2004. Rice yields decline with higher night temperature from global warming. Proceedings of the National academy of Sciences of the United States of America 101, 9971-9975.

Peng, S., Tang, Q., Zou, Y., 2009. Current Status and Challenges of Rice Production in China. Plant Production Science 12, 1-6.

Potapov, P., Hansen, M.C., Stehman, S.V., Loveland, T.R., Pittman, K., 2008. Combining MODIS and Landsat imagery to estimate and map boreal forest cover loss. Remote Sensing of Environment 112, 3708-3719.

Qiu, B., Li, W., Tang, Z., Chen, C., Qi, W., 2015. Mapping paddy rice areas based on vegetation phenology and surface moisture conditions. Ecological Indicators 56, 79-86.

Reed, B.C., Brown, J.F., VanderZee, D., Loveland, T.R., Merchant, J.W., Ohlen, D.O., 1994. Measuring phenological variability from satellite imagery. Journal of vegetation science 5, 703-714.

Ren, J., Chen, Z., Zhou, Q., Tang, H., 2008. Regional yield estimation for winter wheat with MODISNDVI data in Shandong, China. International Journal of Applied Earth Observation and Geoinformation 10, 403-413.

Rouse Jr, J.W., Haas, R., Schell, J., Deering, D., 1974. Monitoring vegetation systems in the Great Plains with ERTS. NASA special publication 351, 309.

Rouse, J.W., Haas, R., Schell, J., Deering, D., 1974. Monitoring vegetation systems in the Great Plains with ERTS. NASA special publication 351, 309.

Sakamoto, T., Van Nguyen, N., Ohno, H., Ishitsuka, N., Yokozawa, M., 2006. Spatio-temporal distribution of rice phenology and cropping systems in the Mekong Delta with special reference to the seasonal water flow of the Mekong and Bassac rivers. Remote Sensing of Environment 100, 1-16.

Sakamoto, T., Wardlow, B.D., Gitelson, A.A., Verma, S.B., Suyker, A.E., Arkebauer, T.J., 2010. A two-step filtering approach for detecting maize and soybean phenology with time-series MODIS data. Remote Sensing of Environment 114, 2146-2159.

Savitzky, A., Golay, M.J., 1964. Smoothing and differentiation of data by simplified least squares procedures. Analytical chemistry 36, 1627-1639.

Scaramuzza, P., Micijevic, E., Chander, G., 2004. SLC gap-filled products phase one methodology. Landsat Technical Notes.

Schafer, R.W., 2011. What is a Savitzky-Golay filter?[lecture notes]. IEEE Signal processing magazine 28, 111-117.

Sha, Z., Zhong, J., Bai, Y., Tan, X., Li, J., 2016. Spatio-temporal patterns of satellite-derived grassland vegetation phenology from 1998 to 2012 in Inner Mongolia, China. Journal of Arid Land 8, 462-477.

Shen, J., Cui, Z., Miao, Y., Mi, G., Zhang, H., Fan, M., Zhang, C., Jiang, R., Zhang, W., Li, H., Chen, X., Li, X., Zhang, F., 2013. Transforming agriculture in China: From solely high yield to both high yield and high resource use efficiency. Global Food Security 2, 1-8.

Shibayama, M., Akiyama, T., 1989. Seasonal visible, near-infrared and mid-infrared spectra of rice canopies in relation to LAI and above-ground dry phytomass. Remote Sensing of Environment 27, 119127.

Son, N.T., Chen, C.F., Chen, C.R., Minh, V.Q., Trung, N.H., 2014. A comparative analysis of multitemporal MODIS EVI and NDVI data for large-scale rice yield estimation. Agricultural and Forest Meteorology 197, 52-64.

Song, H., Huang, B., 2013. Spatiotemporal satellite image fusion through one-pair image learning. Geoscience and Remote Sensing, IEEE Transactions on 51, 1883-1896.

The R Core Team, 2014. R: A Language and Environment for Statistical Computing, R Foundation for Statistical Computing, Vienna, Austria.

Tucker, C.J., 1979. Red and photographic infrared linear combinations for monitoring vegetation. Remote sensing of environment 8, 127-150.

USGS, 2016. Land processes distributed active archive centre (LP DAAC): Surface Reflectance 8-Day L3 Global 250m. 
Van Niel, T.G., McVicar, T.R., 2004. Determining temporal windows for crop discrimination with remote sensing: a case study in south-eastern Australia. Computers and Electronics in Agriculture 45, 91-108.

Wang, Q., Shi, W., Li, Z., Atkinson, P.M., 2016. Fusion of Sentinel-2 images. Remote Sensing of Environment 187, 241-252.

Wang, Y.-y., Yang, Y.-X., 2001. Effects of agriculture reclamation on the hydrologic characteristics in the Sanjiang Plain, China. Chinese Geographical Science 11, 163-167.

Wu, W.-b., Peng, Y., Tang, H.-j., Zhou, Q.-b., Chen, Z.-x., Shibasaki, R., 2010. Characterizing spatial patterns of phenology in cropland of China based on remotely sensed data. Agricultural Sciences in China 9, 101-112.

Xiao, X., Boles, S., Frolking, S., Li, C., Babu, J.Y., Salas, W., Moore, B., 2006. Mapping paddy rice agriculture in South and Southeast Asia using multi-temporal MODIS images. Remote Sensing of Environment 100, 95-113.

Xiao, X., Boles, S., Liu, J., Zhuang, D., Frolking, S., Li, C., Salas, W., Moore, B., 2005. Mapping paddy rice agriculture in southern China using multi-temporal MODIS images. Remote sensing of environment 95, 480-492.

Xing, B., Dudas, M., Zhang, Z., Xu, Q., 1994. Pedogenetic characteristics of albic soils in the Three River Plain, Heilongjiang province. Acta Pedologica Sinica 31, 95-104.

Yale Center for Earth Observation, 2013. Filling Gaps in Landsat ETM Images.

Yuan, Z.-h., Lu, X.-g., Zhou, J., 2006. Cumulative effects of different cultivating patterns on properties of albic soil in Sanjiang Plain. Chinese Geographical Science 16, 133-140.

Zhang, F., Zhu, X., Liu, D., 2014a. Blending MODIS and Landsat images for urban flood mapping. International Journal of Remote Sensing 35, 3237-3253.

Zhang, G., Xiao, X., Dong, J., Kou, W., Jin, C., Qin, Y., Zhou, Y., Wang, J., Menarguez, M.A., Biradar, C., 2015. Mapping paddy rice planting areas through time series analysis of MODIS land surface temperature and vegetation index data. ISPRS Journal of Photogrammetry and Remote Sensing 106, 157-171.

Zhang, H., Chen, J.M., Huang, B., Song, H., Li, Y., 2014b. Reconstructing seasonal variation of Landsat vegetation index related to leaf area index by fusing with MODIS data. IEEE Journal of Selected Topics in Applied Earth Observations and Remote Sensing 7, 950-960.

Zhang, X., Friedl, M.A., Schaaf, C.B., Strahler, A.H., Hodges, J.C., Gao, F., Reed, B.C., Huete, A., 2003. Monitoring vegetation phenology using MODIS. Remote sensing of environment 84, 471-475.

Zhu, X., Chen, J., Gao, F., Chen, X., Masek, J.G., 2010. An enhanced spatial and temporal adaptive reflectance fusion model for complex heterogeneous regions. Remote Sensing of Environment 114, 2610-2623. 